\title{
CORRECTION
}

\section{Correction to: Complete genome sequence of a novel bacteriophage, PBKP05, infecting Klebsiella pneumoniae}

\author{
Hyun Keun $\mathrm{Oh}^{1} \cdot$ Kyoungeun $\mathrm{Cha}^{1,2} \cdot$ Yoon Jung Hwang ${ }^{1} \cdot$ Jaehak $\mathrm{Cho}^{1} \cdot$ Yunyeol Jo ${ }^{1} \cdot$ Heejoon Myung ${ }^{1,2}$ (I)
}

Published online: 21 June 2019

(c) Springer-Verlag GmbH Austria, part of Springer Nature 2019

\section{Correction to: Archives of Virology (2019) 164:885-888}

https://doi.org/10.1007/s00705-018-04121-9

Unfortunately, the original article was published with incorrect accession number and the correct version is updated here.

The GenBank accession number appearing in 2nd line of "Characterization of the genome" in "Results and Discussion" section ( $\mathrm{p} 886$ ) should be replaced by the correct number MH885472.1.

Publisher's Note Springer Nature remains neutral with regard to jurisdictional claims in published maps and institutional affiliations.

The original article can be found online at https://doi.org/10.1007/ s00705-018-04121-9.

Heejoon Myung

hjmyung@hufs.ac.kr

1 Department of Bioscience and Biotechnology, Hankuk University of Foreign Studies, Yongin, Gyung-Gi Do 17035, Korea

2 Bacteriophage Bank of Korea, Yongin, Gyung-Gi Do 17035, Korea 